\title{
DEFENSA DEL TERRITORIO NASA FRENTE A UN PARQUE NACIONAL
}

\author{
DIANA CORREA V. ${ }^{1}$
}

Manizales, 2010-01-21 (Rev. 2010-05-15).

\section{RESUMEN}

En Colombia, las autoridades de Parques Nacionales Naturales y algunas autoridades de los Resguardos Indígenas, pretenden coordinar actividades para la conservación de las áreas protegidas, a través de la aplicación de la "Política de Parques con la Gente" con base en la legislación de protección ambiental y cultural. Sin embargo, estas áreas protegidas tienen razones jurídicas, económicas y sociales, que dificultan el desarrollo de acuerdos para la protección y conservación de la diversidad biológica y cultural. A partir de un estudio de caso, sobre el relacionamiento entre los funcionarios del Parque Nacional Natural Nevado del Huila y los líderes de los Resguardos Indígenas Nasa de Toribío, se realizará la descripción de tensiones existentes entre las partes, con el fin de que la experiencia obtenida durante el desarrollo de esta etnografía sea de utilidad para aquellas personas que trabajan en favor de la conservación de las áreas protegidas.

\section{PALABRAS CLAVE:}

Medio ambiente, comunidades indígenas, Parques Naturales, Resguardo Nasa de Toribío, Parque Nacional Natural Nevado del Huila, Cauca.

\section{DEFENSE OF THE NASA TERRITORY AGAINST A NATIONAL PARK}

\begin{abstract}
In Colombia the Natural National Parks authorities and some Indigenous reservation authorities intend to coordinate activities aimed at the conservation of protected areas, by means of the application of the "Parks with People" Policy based on the legislation for environmental and cultural protection. However, these protected areas possess judicial, economical and social reasons that complicate the development of agreements for the protection and conservation of the biological and cultural diversity. Based on a study case, on the relationship between employs of the Natural National Park Nevado del Huila and the leaders of the Nasa Toribio Indigenous reservation, a description of the tensions between both parties will be carried out, in order to promote de usefulness of the ethnographical experience among the people that work in favor of the conservation of protected areas.
\end{abstract}

KEY WORDS: environment, indigenous communities, Natural Parks, Nasa Toribio Native Reservation, Natural National Park Nevado del Huila, Cauca. 


\section{INTRODUCCIÓN}

Colombia ha sido catalogada como un país "megadiverso" ${ }^{2}$ gran parte de esta diversidad biológica se encuentra en los Parques Nacionales Naturales (PNN) que hoy suman el $11 \%$ del territorio en 11 '600.000 hectáreas, y en los Resguardos Indígenas (RI) que son dueños del 27\% (36'500.416 ha) del territorio nacional.

De acuerdo con el Artículo 63 de la Constitución los PNN y los RI son inalienables, imprescriptibles e inembargables y además cumplen con la función ecológica de propiedad. De acuerdo con el Artículo 7 del Decreto 622 de 1977, el traslape o superposición entre estas dos áreas no es incompatible, la realidad social supera el ideal legal, y produce desencuentros entre los encargados de implementar la legislación y las comunidades que habitan los Parques.

En Colombia existen 17 áreas del sistema de PNN traslapadas con más de 45 Resguardos, y para aprovechar el potencial de conservación ambiental y aportar a la solución de las diferencias entre autoridades ambientales y autoridades indígenas, la Unidad Administrativa especial, propuso en el año 2001, "la política de participación social en la conservación" (www.parquesnacionales.gov.co). También se han firmado convenios marco con las comunidades indígenas Bora Miraña en el Cahuinarí, con las comunidades Nasa de Toribío (Cauca) y "a la fecha se han firmado dos acuerdos enmarcados en la estrategia de Régimen Especial de Manejo entre el PNN Catatumbo Barí y el Pueblo Barí (Junio de 2007) y entre el PNN Paramillo y el Resguardo Indígena Yaberaradó (Diciembre de 2007)" (comunicación personal con el área de participación social Parques Naturales, julio de 2008).

Estas políticas y convenios también son producto de las demandas de reivindicación de los derechos, hechas por indígenas basados en: la Constitución Política (Art. 7, 8, 63, entre otros), el Convenio 169 de la OIT sobre pueblos indígenas y tribales, el Convenio de Diversidad Biológica (Art. 8j) y la participación de la academia con diferentes estudios antropológicos sobre la relación entre comunidades indígenas y medio ambiente (Correa, 2000; Pineda, 1999, p. 264-283; Ulloa, 2001) que describen una visión diferenciada entre las culturas indígenas y las occidentales frente a la naturaleza.

En el ámbito internacional, organizaciones ambientales de reconocido prestigio internacional como la WWF y la UICN han propuesto políticas para la conservación, con la participación de comunidades indígenas y evidencian mediante estadísticas "la simbiosis entre diversidad natural y cultural", y proponen que: "En los países con megadiversidad biológica en relación con el endemismo lingüístico, deberán formular propuestas para la conservación de las prácticas tradicionales de manejo a nivel de ecosistemas, hábitats y especies, prevención y control de impactos ambientales en este tipo de territorios, y la creación de incentivos y distribución de beneficios para las comunidades" (Oviedo, 1999, p. 1-12).

Por su parte, las comunidades indígenas han defendido su derecho a cuidar con autonomía y una mínima intervención estatal las áreas que se superponen, argumentado que, con base en planes de vida y planes de ordenamiento territorial, los Parques Naturales deben ser gobernados con autonomía.

Aunque cada traslape entre un PNN y un RI, tiene características propias, el artículo que aquí presentamos, describe el conflicto que surge al intentar implementar la política de "Parques con la gente" en el Parque Nacional Natural 
Nevado del Huila y la política de resistencia de los Resguardos Indígenas Nasa de San Francisco, Toribío y Tacueyó, en el municipio de Toribío (Cauca).

Los datos aquí expuestos fueron compilados durante los años 2003 y $2004^{3}$, mediante la aplicación del método etnográfico, la participación activa en reuniones, discusiones de grupo, recorridos por el territorio Nasa, desarrollo de entrevistas y elaboración de un diario de campo para registrar las impresiones producidas por la interacción entre los líderes indígenas y los servidores públicos del Parque.

\section{RESISTENCIA Y RECUPERACIÓN}

\section{Raíces del árbol de la resistencia}

La resistencia indígena hunde sus raíces en la nieve de la historia y por lo tanto es la propia historia de los legítimos dueños de América, y es gracias a esta resistencia ancestral que nos hemos mantenido como pueblo.

Guardar, cuidar, defender, preservar, pervivir, soñar los propios sueños, oír las propias voces, reír las propias risas, es y ha sido la razón de su existencia, porque no existe como una gélida estructura, sino que habita en la mirada, la voz y el corazón Nasa. (ACIN, CRIC, ONIC, 2002, p. 9)

Nosotros decimos vamos a producir agua, vamos a producir bosque, vamos a producir naturaleza, ¿de qué manera vamos a llegar allá? Nosotros somos muy recelosos en ese sentido. (Palabras de un comunero en asamblea, Toribío, febrero de 2004)

Durante los últimos veinte años, los cambios en las concepciones étnicas y ambientales, promovidas desde la Constitución Política y los Convenios Internacionales, han ampliado los horizontes y las oportunidades para la promoción y gestión de estos temas desde el ámbito local. En Toribío, los líderes indígenas argumentan que después de quinientos años de explotación es el momento de retomar las riendas de su vida como pueblo, de ser amos y señores de lo que sucede en su territorio e impedir las intromisiones externas que los sometan o perjudiquen.

Recorrer el camino de la autonomía implica dudar y cuestionar las prácticas y discursos de los actores foráneos, así como su relación con estos. En palabras suyas: "trabajamos para los blancos durante quinientos años, ya es hora de que ellos empiecen a trabajar para nosotros".

Consideran que por medio de las semillas manipuladas, los químicos, la televisión, la radio y "las ideas que vienen de afuera", se ha creado un "sistema que los está encautivando", pero que estos medios también pueden ser utilizados a su favor creando nuevas oportunidades: ¿Cuál es el mejor camino para controlar la situación que los afecta? ¿Cómo hacer cumplir los derechos enunciados en políticas y leyes? ¿Cómo obtener ventajas en la interacción con los otros, con los que no son Nasa? ¿Cómo evitar la dependencia externa y ser autosuficientes?

El traslape con el Parque Nevado del Huila se sitúa en este contexto, y las funciones de los representantes del Estado son cada vez más cuestionadas: esta superposición es fuente de tensiones y contradicciones entre las partes. Los líderes Nasa argumentan que existe una amenaza contra su autonomía y el 
manejo de los recursos naturales en su territorio, y temen la posibilidad de que se firmen tratados con empresas transnacionales que les arrebaten sus derechos. Por otra parte, muchos de los servidores públicos de los Parques piensan que las comunidades indígenas no son tan conservacionistas como la ley y la política pretenden ya que encuentran deteriorados esos territorios; les es difícil entender sus costumbres, su papel en la conservación, el sistema de toma de decisiones y sus intentos de inserción en la modernidad mediante la creación de pequeñas industrias.

En el Parque Natural Nevado del Huila la puesta en práctica del relacionamiento entre las partes ha sido conflictiva. Los líderes Nasa hacen constantes reivindicaciones sobre el papel del Estado en su territorio, cuestionando los contratos, las leyes, las políticas y las prácticas que los servidores públicos del Parque intentan desarrollar en las áreas de traslape. ${ }^{4}$

Mientras sobre los líderes indígenas recae la obligación de aclarar cada situación, propuesta o proyecto, y dar respuesta a las preguntas para cada caso en su interacción con el Parque, los otros miembros de la comunidad hacen parte del movimiento social participando en asambleas, marchas, protestas, o guardando silencio frente a las preguntas hechas por los funcionarios, dicen que no entienden, demuestran desconcierto y desconfianza o proponen que se consulte al Cabildo.

\section{PARA NO “DEJARSE ENCAUTIVAR"}

Se ha cambiado la forma de vivir, de trabajar la tierra, de pensar. Tenemos que comprar lo que la industria produce; los jóvenes le llamamos sistema. [...] Yo creo que es no dejarse encautivar de muchas cosas para no perder lo que es de uno. Yo he analizado con otros jóvenes y ellos dicen que algunas cosas ya no se recuperarían. La mitad no. La mitad si. (Entrevista con un miembro del Equipo Económico Ambiental, Toribío, febrero de 2003)

En sus constantes diálogos en la asamblea, con los mayores y the'walas (ver Glosario) los jóvenes líderes han aprendido a realizar sanas críticas a su entorno, al estado de la naturaleza y a la pérdida de costumbres; en el análisis que realizan, se culpa a los foráneos de proponer un sistema que los está encautivando.

Los indígenas Nasa suelen diferenciar el adentro del afuera, es decir, diferencian los asuntos internos que nacen y se deciden en la comunidad, de los asuntos externos, propuestos por los "blancos"; observando estos últimos como una posible amenaza a la comunidad; en consecuencia, los comuneros deben estar atentos a las propuestas, políticas, y apoyos económicos, que estos traen de afuera, dando una mayor credibilidad a las propuestas que nacen en la asamblea, los Cabildos y las organizaciones indígenas que convocan a los cabildos como la CWK, el CRIC y la ONIC (ver Siglas).

El análisis de los cambios culturales de Toribío realizado por uno de los líderes del Equipo Económico Ambiental, tiene en cuenta la existencia de un sistema que los "está encautivando". Este sistema se manifiesta de diferentes formas (Hardt \& Negri, 2001, p. 1-12) y por ello se deben adoptar diferentes medidas con el fin de contrarrestar sus efectos. Los mensajes del sistema están en la televisión, la radio, el Internet; o en los productos que se compran en Santander de Quilichao, como las semillas de maíz que sólo sirven para una cosecha y obligan al campesino a seguir comprándolas por fuera de Toribío, creando dependencia del mercado. Existe rechazo frente al ingreso de productos 
transgénicos, la fumigación con glifosato y la posibilidad de apropiación de los recursos naturales por parte de empresas transnacionales.

\section{EDUCAR E INVESTIGAR}

Cuando llegó por primera vez a la escuela, Rosario tuvo que hacer tres veces primero de primaria porque sólo podía hablar y comprender Nasa yuwe, pero recibía las clases en español. La profesora y los compañeros creían que "la india Rosario es una bruta" y ella tuvo que soportar durante años esta doble discriminación.

En la educación indígena la resistencia empieza por la lengua y la manera de nombrar los montes, los ríos y los seres queridos; por tal razón en Toribío existe una campaña para la recuperación del Nasa yuwe. El adulto puede asistir a la escuela de Nasa yuwe, mientras que al niño se le estimula desde la escuela, o por sus padres si estos aún la conservan. Gracias al cambio en el concepto y el curriculum educativo, el conocimiento aplicado a la huerta tull, el tejido, la lengua y la motivación ambiental hacen que hoy personas como Rosario sean líderes importantes en el proceso.

Durante los últimos 20 años se han creado nuevas escuelas, como el Centro de Etnoeducación Indígena (CECIDIC) que destaca lo agrosilvopastoril y los Centros de Etnoeducación Comunitaria para el Fortalecimiento del Plan de Vida Nasa.

Los Centros de Etnoeducación son una estrategia de la organización indígena que pretende formar y capacitar personas de la comunidad en los diversos aspectos requeridos por el Plan de vida buscando que la comunidad consolide sus proyecciones a corto, mediano y largo plazo, fortaleciendo la identidad para proyectar los valores a futuras generaciones en lo político-organizativo, lo económico-ambiental y lo socio-cultural buscando potenciar y equilibrar las relaciones internas y externas con otros pueblos del mundo. (Cabildos Indígenas de Toribío, San Francisco y Tacueyó, 2001)

Una escuela propia de formación económica-ambiental con currículo propio y plan de estudios con criterios de participación, que sea capaz de responder a las necesidades y expectativas en la formación política, técnica, étnica y profesional como espacio de análisis y reflexión para la consolidación de la política ambiental propia. (ACIN, CRIC, ONIC, 2002)

En el norte del Cauca se indaga sobre el derecho, la economía y el arte como una "estrategia de organización indígena". Los líderes Nasa alientan esta estrategia argumentando que "de nada sirve recuperar la tierra, si no se recupera la lengua, la cultura, y la economía". Por esta razón el "proceso comunitario" debe estar alerta en los diferentes aspectos de la vida cotidiana y la población debe "investigar lo propio y no dejar que se lo roben". Las escuelas comunitarias cumplen un importante papel en la (re)creación de lo propio: los jóvenes deben hablar con sus abuelos sobre la historia, la espiritualidad y la cosmovisión para mantenerlas vivas. El importante papel del indígena en la conservación de la naturaleza debe pervivir, los ojos de agua y los páramos deben conservarse. Pero también las escuelas cumplen un rol destacado en la recreación y la reproducción de una cultura diferente a la occidental, cuestionando ese sistema que "los está encautivando", que los hace "estar en vida pero dominados", que no les permite valorar lo que les es propio. 


\section{LOS LÍDERES}

En Toribío, algunos hombres y mujeres se distinguen de otros por su arrogancia en el andar y su postura erguida que los hace notables; su presencia es tan altiva que parecen más altos que sus compañeros. Cuando caminan siguen su ruta sin mirar a nadie, pero cuando hablan, lo hacen con voz recia, mirando fijamente al auditorio que se mantiene en silencio, interrumpido de vez en cuando por el rodar del hilo dentro de una jigra.

Los discursos pueden ser largos, de una o dos horas, con interpelaciones breves en las cuales otros refuerzan las ideas del líder. En algunos casos, la perorata puede iniciar y terminar con un regaño para los asistentes. La mirada es penetrante y mucho más si se trata de encarar a los foráneos, de expresar ideas, convencer, obligar. Hablan ante la asamblea de la resistencia, la recuperación y el proceso. Lucen recios, valientes, y sin demostrar miedo a la muerte, hacen gala de las principales cualidades de un(a) líder Nasa.

En relación con las recuperaciones, éstas son: "orientadas por un núcleo muy visible de actores, los líderes de la organización indígena, quienes promueven procesos de recuperación cultural y lingüística y de ampliación territorial a partir de estrategias de reinvención de su identidad étnica" (Dover y Rappaport citados en Chaves, 2001, p. 238). Para ellos, la construcción de la identidad indígena es requisito indispensable en la negociación con el Estado y los actores internacionales, dando cumplimiento a la premisa de que "A mayor conservación de usos y costumbres, mayor autonomía".

\section{MINGAS DEL PENSAMIENTO, MARCHAS Y MALICIA INDÍGENA}

Chantal Mouffe y Ernesto Laclau argumentan que el trabajo político urgente en este momento histórico es la búsqueda de una democracia radical y plural. Abogan por diversas formas para que los individuos ejerzan presión sobre las democracias, por una justicia social, económica y ambiental más amplia. (citado en Warren, 2001, p. 201)

Para construir democracia se requiere de actores fuertes y representativos, capaces de hacer valer los intereses de sus representados dentro del sistema político. A partir de la promulgación de la Constitución de 1991, las comunidades indígenas colombianas han logrado su visibilización ante el Estado y han sido reconocidas como dueñas de un territorio, poseedoras de una jurisdicción especial, con diferentes formas de gobierno, lengua y cosmovisión, así como su representación en el Congreso de la República y la transferencia de recursos económicos por parte del Estado, entre otros derechos; lo que busca consolidar nuestro país como una Nación pluriétnica y pluricultural.

Pero los derechos enunciados deben ser provistos de contenido y es en la definición de éstos donde el movimiento indígena busca avanzar y consolidar opciones económicas, políticas, sociales y ambientales. Para lograr este objetivo se entreteje una delicada telaraña de poderes, en la que los líderes establecen un pulso con los servidores públicos encargados de aplicar las políticas gubernamentales ${ }^{5}$, como un medio más de regular o dirigir las acciones de los actores sociales.

Mientras los servidores públicos del PN intentan encausar a los líderes en su deber de conservación ambiental, en la implementación de la función ecológica de la propiedad (Art. 58 de la CP) mediante la aplicación de la Política de 
Participación Social en la Conservación, los líderes indígenas aprovechan este discurso ambientalista jurídico, político y social, para dirigir la financiación a los planes y proyectos "propios" de la comunidad, en busca de la solución de los problemas más urgentes, como la seguridad alimentaria, y la supervivencia en medio de la guerra, que se vive a diario en Toribío.

Hasta dónde llegan los derechos y cómo deben aplicarse son la respuesta que se obtiene desde cada caso concreto: en las sentencias de los jueces y las Cortes, en las políticas institucionales y en el quehacer de los activistas y defensores de los derechos indígenas. A nivel nacional se debate la compensación por el deterioro ambiental causado por la creación de la represa de Urrá en el Parque Nacional Natural Paramillo y el territorio indígena Embera, la participación indígena Wayúu en el manejo de las salinas de Manaure y las minas del Cerrejón en La Guajira.

En el Cauca las principales tareas ambientales de los líderes Nasa están relacionadas con el ejercicio de la autonomía y la reciprocidad, buscan restablecer el desequilibrio causado por el deterioro ambiental que existe en la parte plana; los Nasa plantean los valores de armonía y reciprocidad a los industriales y cañeros, para que contribuyan con aportes económicos destinándolos a la conservación de los nacimientos y ojos de agua que sustentan la cuenca del río Palo. "Si el agua baja que la plata suba" les dicen los líderes a los industriales, refiriéndose a la cuenca del río Palo, uno de los principales tributarios del río Cauca, imprescindible para el sostenimiento de la industria y el monocultivo.

Por medio de resoluciones creadas por el CRIC o la CWK, han hecho propuestas pertinentes ante la legislación estatal en aspectos como la creación de un plan de manejo de la cuenca del río Palo hecho por y para los indígenas (CWK, Resolución 004 de 2003), que obre directamente sobre los recursos generados en las tasas retributivas por contaminación del agua (Ley 99 de 1993, Decretos 1729 y 1604 de 2002) que deberán pagar los industriales de la parte plana a quienes conservan el agua en la parte alta dentro del principio de la reciprocidad; proponen la creación de una Corporación Ambiental Indígena que coordine acciones con Corporaciones Autónomas Regionales (Ley 99 de 1993); el control directo de los proyectos ambientales que se están ejecutando sobre el territorio como el Proyecto Biomacizo (CRIC, 2004); y la modificación al proyecto de ley de páramos. (Propuesta CRIC et al., 2004, frente al proyecto de Ley 032 de 2004).

La legitimación de las relaciones sociales de desigualdad y la lucha por transformarlas son preocupaciones centrales de la Política Cultural. Fundamentalmente, ésta determina los significados de las prácticas sociales, y más aún, determina también cuáles grupos o individuos tienen el poder para definir dichos significados. La política cultural también se preocupa por la subjetividad y la identidad, puesto que la cultura juega un papel crucial en la constitución de nuestro sentido de nosotros mismos [...] las formas de subjetividad que habitamos juegan un papel central en determinar si aceptamos o cuestionamos relaciones de poder existentes. Más aún para grupos marginales y oprimidos, la construcción de identidades nuevas y de resistencia es una dimensión crucial de una lucha política más amplia en la transformación de la sociedad. (Jordan y Weedon, 1995 citados en Escobar, Álvarez \& Dagnino, 2001, p. 23)

Para dar una mayor legitimidad a su lucha política, los líderes Nasa sostienen que su propuesta nace y se desarrolla en la comunidad en las "mingas del pensamiento" y se da a conocer mediante marchas y movilizaciones. 
La gigantesca marcha indígena del año 2003 desde Santander de Quilichao a Cali, compuesta por negros, indígenas, campesinos, estudiantes y otros simpatizantes, fue calculada en más de 60.000 participantes. Podía leerse en los carteles, pregones y cintas de colores que portaban tantos marchantes sudorosos, lemas que ponían en cuestión a gobernantes, actores armados, e incluso alarmaban al desprevenido transeúnte al demostrar la enorme fuerza del movimiento social indígena. En sus arengas manifiestan su rechazo a "las continuas guerras por políticas de exterminio físico y cultural y a la imposición de un modelo económico capitalista basado en el consumo y en el libre comercio y en este sentido, la imposición de normas transnacionales de comercio como el ALCA y TLC" (ACIN, CRIC, ONIC, 2002). También se exige que estos acuerdos no se realicen a espaldas de los directos afectados.

Protestan contra el uso de los transgénicos que afectan los cultivos tradicionales, la salud humana y disminuyen gravemente la biodiversidad (Altieri, 2003) así como la fácil concesión de patentes, tal y como se pretende establecer en el TLC (Tratado del Libre Comercio).

Las movilizaciones también tienen como objetivo hacer públicos los logros indígenas en cuanto a la planeación y el gobierno que tienden a la conservación de la naturaleza, especialmente en el cuidado de los ojos de agua y los afluentes de los cuales depende el río Cauca, imprescindibles para la existencia de los cientos de miles de habitantes de la región que dependen del agua para vivir; para conservar el agua, insisten, se requiere conservar los páramos y, para lograr esto último, se debe reubicar a sus pobladores mediante la adquisición de nuevas tierras en la parte plana, sin abandonar la propiedad y gobernabilidad indígena de la parte alta.

\section{OCULTAR Y CALLAR}

Sus ojos van al suelo, me miran un segundo, sonríen, y vuelven a mirar el suelo. Si pregunto con insistencia sobre un tema del cual no quieren hablar, me dan la espalda con risitas ahogadas, diciendo "yo de eso si que no sé", "hay que esperar", "hay que hablar con el Cabildo". Esta respuesta, tantas veces escuchada por los que venimos de afuera, ha creado una fama entre los foráneos de que el Nasa es malicioso, terco y callado, que no sabe lo que quiere y se demora mucho para tomar cualquier decisión.

Solamente después de varias reuniones pude comprender otra estrategia: la del silencio. El visitante esporádico puede pensar que son tímidos, pero no lo son; por el contrario, les encanta expresar sus puntos de vista. Sin embargo, sólo lo hacen después de saber quién es, porqué y para qué la persona allí presente solicita la información. Ante las preguntas de los extraños la población suele responder con silencio. No hablan con extraños hasta que no exista el reconocimiento público del visitante, alguna autorización del Cabildo, o en determinados eventos como las asambleas. El silencio y la dilación pueden desesperar al visitante. Pero el Nasa tiene la intención de ocultar las semillas, los conocimientos, y otras cosas, así que lo que a los ojos del "blanco" parece timidez, cerrazón, o quizás falta de inteligencia, es parte de un aprendizaje colectivo que busca proteger, defender y callar ante la duda, ante la posible intromisión de los que vienen de afuera.

Ocultar y silenciar hace parte del manejo que las autoridades Nasa le han dado a la información que se produce en su territorio: los Planes de Ordenamiento Territorial, Planes de Vida, el Plan Ambiental Indígena -PAl-, entre otros instrumentos de planeación, no pueden consultarse y existe una demanda contra 
la Corporación Autónoma Regional del Cauca por el uso indebido de la información. A pesar de los convenios firmados con el Parque Nevado del Huila durante 2003 y 2004 no se pudo tener acceso institucional a sus bases de datos.

En el Cauca aprendí a callar. Cuando el nivel de agresión en un grupo es muy fuerte, tan sólo el silencio puede contrarrestar el grito del otro. Aprendí a mirar a quienes gritaban y estar orgullosa dentro de un ruidoso silencio. El silencio también fue invaluable en los combates entre la fuerza pública y las FARC porque entendí que al ocultar el miedo, no generaría angustia en el otro. Aprendí también a no preguntar a destiempo y a soslayar un tema inoportuno. El silencio es fuerza y les crea oportunidades para analizar y responder más tarde cuando los pensamientos han sido "volteados", comenzado por la derecha y saliendo por la izquierda en una limpieza frente a un río, analizados en grupo, o por delegación a la autoridad indígena.

\section{¿PARQUES CON LA GENTE?}

"Parques con la gente", es el principal lema social de la UAESPNN; pero es necesario indagar si están los indígenas, los negros y los campesinos de acuerdo con los Parques en sus territorios. Desde su creación, ha existido conflicto entre los Parques y los pobladores asentados en estas áreas, denominadas patrimonio mundial para la conservación. En el pasado, la razón fundamental del conflicto fue la de haberlos creado sin consultar a sus habitantes, excluyendo al hombre de su entorno, desconociendo su papel en la conservación y creando una dicotomía entre el hombre y la naturaleza. Esta última era vista como algo para investigar, controlar, proteger y conservar, dentro de un área demarcada para su protección de manera unilateral por el Estado.

El actual conflicto entre el Parque Nevado del Huila y los indígenas de Toribío, está relacionado con el temor de los Nasa frente a la apropiación foránea de los recursos naturales existentes en su territorio a través de la firma de tratados internacionales como el TLC, que busca patentar los conocimientos y el material vivo, o la venta de cualquier "recurso natural" que tenga precio y pueda ser comercializado (Escobar \& Álvarez, 1996, p. 110; Escobar, 1999) como la venta de agua y petróleo, temas sensibles en varias partes del globo terrestre.

Pero entonces, ¿quién es el beneficiado en el manejo de los recursos naturales? En primera instancia la beneficiada debe ser la naturaleza misma, que a diferencia de los humanos no tiene voz, pero puede hablar a través de "derrumbos" e inundaciones, tal como lo enseñan algunos viejos the'walas con gran elocuencia, digo yo. En segunda instancia, los pobladores de Toribío, que aún disfrutan del agua pura y sin contaminar, pero también acostumbran quemar las montañas durante el verano sin atender las advertencias realizadas por las autoridades ambientales locales.

También se considera que la conservación ambiental debe ser tanto un asunto de todos como una preocupación global. Reconforta observar cómo en muchas partes del mundo, la gente del común comienza a cambiar sus hábitos diarios de consumo, a sopesar sus elecciones desde la utilización diaria de determinado medio de transporte (bicicleta, transmilenio, o el carro particular); los alimentos que toma (¿consumo mote, o enlatados de supermercado?, ¿agua del río, o agua en botella plástica?, ¿a dónde van a parar los plásticos y latas que desecho?), o al alzar la voz en contra de la implementación de cultivos transgénicos, la aceptación sumisa del ALCA, el TLC y las estrategias económicas que amplían cada vez más las injusticias económicas en el mundo. 
A pesar de los esfuerzos institucionales de la UAESPNN por reconciliarse con los pobladores indígenas de los Parques Nacionales, aportando a la consolidación de las actividades propuestas desde la localidad e intentando construir confianza a partir de procesos que se construyen de abajo hacia arriba, los Parques Nacionales en el norte del Cauca, y específicamente en Toribío, son una entidad legal que produce desconfianza y resistencia.

\section{LA MALICIA INDÍGENA ANTE EL PARQUE NEVADO DEL HUILA}

Aunque desde diciembre de 2000 se firmó un convenio de cooperación interinstitucional entre la UAESPNN - Parque Nevado del Huila, los cabildos de Tacueyó, San Francisco, Toribío y la Alcaldía de Toribío, la operativización y ejecución de éste se ha dado lentamente sin demostrar avances significativos. Las reuniones para ejecutar el Convenio se dan sin periodicidad alguna, dependiendo de la última discusión entre las partes, y es difícil coordinar agendas para realizar los encuentros; quizás por falta de voluntad o por las múltiples ocupaciones de las partes. Dentro de las ocupaciones de los líderes indígenas se encuentra el representar a la organización indígena en diversos sitios de Colombia y en otros países, mientras los dinamizadores ambientales del EEA asumen los compromisos de capacitación en las veredas, o bien deben recibir charlas de la ONIC, de las ONG ambientales, realizar ejercicios de planeación y responder a los financiadores de los proyectos; de igual manera, los líderes de Parques deben cumplir con sus obligaciones en los sectores del Tolima y el Huila, y cubrir sus funciones en las 158.000 hectáreas del PNN del Huila.

Generalmente las reuniones se realizan los fines de semana; los asistentes por parte del PNN Nevado del Huila llegamos de Popayán en un carro prestado o alquilado, debido a que los del Parque han sufrido diferentes siniestros como hurtos y bombas explosivas. El viaje se sucede en medio de la incertidumbre por la situación de orden público y por la tensa relación que se vive con los líderes de Toribío.

A pesar de ello, durante las tres horas de camino los "empleados del Parque" intentábamos crear un ambiente cálido realizando bromas sobre la situación que nos cobija: hablamos de nuestra eficaz estrategia de la cucaracha, "si los indios nos sacan a escobazos, nosotros intentamos nuevamente entrar. Si nos sacan de Toribío, entramos por Tierradentro, si nos sacan de Tierradentro nos metemos por Gaitania". Componemos canciones sobre los convenios interinstitucionales: la última "complacencia", dedicada al convenio con Toribío, fue compuesta por Darío Gómez: "La que se va de mí, se va, se fue. La que se va de mí, le digo adiós, adiós".

La situación de orden público también es fuente de inspiración: "este fin de semana nos vamos para una toma, y no de chicha ni de aguardiente precisamente: una toma de orden público".

En el corregimiento del Palo, que es la divisoria territorial entre la zona plana y la parte alta, entre los paramilitares y la guerrilla, entre los carros con placas y los "torcidos", escenario constante de ajusticiamientos entre los distintos actores armados, acuden a recogernos los dos delegados indígenas del EEA encargados de nuestra "seguridad" hasta Toribío. Es que, por lo menos, pueden dar razón del porqué se encuentran estos extraños en el territorio indígena frente a cualquiera que solicite información al respecto. 
Los asistentes por parte de Parques son: la coordinadora del programa Nevado del Huila, el profesional 19, y los contratistas financiados por Naciones Unidas para el convenio, la nodo centro, la planificadora en cuencas hidrográficas, la bióloga de la conservación de Toribío, la profesional social y el profesional de sistemas sostenibles para la conservación.

Por parte de Toribío asisten los coordinadores del cabildo económico ambiental por San Francisco, Tacueyó y Toribío; el coordinador del Equipo Económico Ambiental (EEA) del municipio, los animadores ambientales del EEA y los contratistas indígenas financiados por el convenio: el planificador en cuencas hidrográficas para el norte del Cauca, y tres operarios indígenas.

Por lo general, los encargados de la negociación y toma de decisiones en estas reuniones son Nelson Lemus y Ezequiel Vitonaz como coordinador del Equipo Económico Ambiental. Cuando por algún motivo éstos no se encuentran, los demás miembros del equipo dicen que no pueden participar ni con su voz, ni con su voto. Sin embargo, sus rostros hablan: las reuniones no están exentas de ceños fruncidos, burlas, negaciones o asentimientos con la cabeza y alguna que otra corta participación que refuerza la argumentación de las voces principales.

Durante la reunión, los miembros del EEA se sientan juntos y los voceros del grupo son aquellos que por su experiencia o por la ocupación de cargos públicos se encuentran legitimados para tomar decisiones. El silencio de muchos contrasta con la voz potente de los dos líderes que dominan la negociación, pero también realza concentración de poder en los líderes principales y la existencia de diferentes niveles de información.

Nelson Lemus es un indígena joven, con una altura superior a la de sus compañeros, nariz y espalda ancha, tiene un carácter recio, que apoya la toma de decisiones fuertes, tal como él lo ha dicho en repetidas ocasiones. Su carrera pública, se inició como operario del Parque Nevado del Huila en 1998; en 2001 fue gobernador del Cabildo de San Francisco y durante más de cuatro años fue coordinador del EEA, razón por la cual es respetado por todos los miembros del Equipo.

Precisamente por haber trabajado en Parques Nacionales, Nelson Lemus se considera conocedor de los inconvenientes que estas áreas protegidas suscitan, entre los principales inconvenientes que él señala se encuentran:

Nos quieren cambiar los nombres como lugar sagrado por zona intangible. Nosotros no somos zona amortiguadora de nadie; dicen que somos un área protegida, y que hacemos parte del Sistema Nacional de Áreas Protegidas. ¿Con autorización de quién?

Nosotros sentimos temor con los Parques Nacionales porque ¿cuál es su relación con el ALCA, los transgénicos, el acceso a los recursos genéticos, las fumigaciones, licitaciones y los megaproyectos.

Eso es lo que llaman apertura económica, el ALCA es eso, son unas empresas muy grandes, con mucha capacidad que se van a meter a hacer el negocio del agua, el negocio del mármol, el negocio del oro...

La estrategia de los Parques Nacionales es utilizar los conocimientos de las comunidades. ¿De qué sirve ser parte de Parques Nacionales, si el Gobierno 
también los fumiga? Tampoco nos dan claridad, ¿qué pasa con la figura de las concesiones de los Parques Nacionales?

Rechaza las reformas del Gobierno para vender los recursos naturales, en especial la concesión de zonas turísticas pertenecientes a los Parques Naturales, que promocionan la participación privada en Tayrona ${ }^{6}$, Amacayacu, Iguaque, Gorgona $y$ los Nevados.

El coordinador del EAA, Ezequiel Vitonaz, es un hombre robusto, moreno y con ojos de mestizo; ha sido camionero, profesor, alcalde de Toribío; es un hombre perspicaz y de carácter conciliador. Por lo general presenta propuestas concretas con el ánimo de continuar adelante, y piensa que sí es posible trabajar con la figura de Parques, siempre y cuando ésta sirva para "apoyar lo propio":

Nosotros vimos que sí hemos podido trabajar con Parques: se han firmado convenios y hemos ido avanzando. Se espera que se pueda hacer un plan de manejo construido entre indígenas y Parques, por ejemplo poder tener una Corporación creada por los indígenas, que pueda decirle a los industriales cuánto deben aportar, para buscar la autonomía de las comunidades indígenas, ya que la Constitución es muy clara en su Artículo 330; lo que buscamos es desarrollar el Artículo 330 en la práctica con Parques. Si las cosas no van para allá, paramos. Podemos hacer manifestaciones paros, etc. Pero si vemos que la institución nos quiere coger de idiotas útiles, pues paramos. No podemos seguir encerrando ojos de agua y que los que toman la plata es Corpopalo o la CRC. Por eso queremos saber cuál es la posición de Parques. Propongo revisar la agenda y que seamos sinceros; éste es el trabajo que yo siempre he buscado, ¿cómo es el manejo conjunto? Es algo que ya veremos.

De manera constante, los líderes relacionan los cambios legales o económicos que afectan a los Parques como la concesión de áreas ecoturísticas (El Tiempo, 2005, p. 1 y 14; El Espectador, 2005, p. 5A), las propuestas de legislación de páramos, la ordenación de las cuencas hidrográficas, etc. con la apertura económica, el TLC y el poder de las empresas transnacionales. Todos estos cambios son analizados como oportunidades de beneficio para aquellos sectores que tienen la capacidad económica necesaria para realizar inversiones, en menoscabo de los intereses indígenas.

\section{LA INFORMACIÓN}

De acuerdo con la Resolución 003 de 2003 proferida por la CWK toda "La información primaria y secundaria que se levante en la zona es de propiedad intelectual colectiva de las comunidades y salen a otros escenarios solo con la autorización de los CABILDOS Y LA CXAB WALA KIWE (CWK)".

Existe también una actitud de todo el equipo ambiental frente al manejo de la información; ésta no debe salir de los resguardos: "Creemos que Parques Nacionales pueden robarnos la información, y eso no lo podemos permitir. En eso tenemos recelo y es un punto que no se concilia".

Jaime Díaz, coordinador del equipo económico ambiental del resguardo de Tacueyó, tenía una posición diferente: "La diversidad y los conocimientos ya se los robaron, en Internet vemos todos los conocimientos del the'wala, los rituales del refresco, y demás. Lo que hay que hacer es recuperarla". 
Debido a los temores existentes frente al tema del hurto de la información, y puesto que los páramos son territorios sagrados, los miembros del EEA transmitieron la voz de los the'walas quienes han sugerido no realizar ningún tipo de caracterización en los páramos, como nos contó Ciro uno de los animadores ambientales:

Nosotros sí nos hemos hecho estas preguntas pero no lo hemos definido completamente en términos de qué se quiere caracterizar, ¿en términos culturales, sociales, económicos, de biodiversidad, de agua, de qué? Cuando las autoridades espirituales nos dijeron que no a las caracterizaciones de los páramos, estas se pararon, y nos decidimos simplemente por la educación en El Crucero.

Aunque los miembros del EEA insisten en que los empleados del Parque son un grupo de personas preparadas ante las cuales no existe ningún problema personal, insisten en que el temor recae sobre el hecho de trabajar para el Estado.

Desde el Parque, intentábamos dar un cauce a los temores del EEA, frecuentemente aludíamos a la necesidad de trabajar juntos en el marco de la política de participación social teniendo en cuenta que quizás existía un tiempo limitado para el trabajo conjunto, como lo sustentaba Jefferson Rojas, el profesional 19 del PNN-NHuila: "Somos un equipo al cual ustedes conocen desde hace tiempo; lo que debemos hacer es aprovechar este cuarto de hora que tenemos y avanzar lo más rápido posible, sin detenernos".

Quienes trabajamos con el Parque éramos conscientes de las contradicciones existentes en el Estado, situaciones como la fumigación y bombardeos de los páramos en los Parques Nacionales, nos daban una sensación de impotencia institucional.

Los cambios en las directivas, la vulnerabilidad de la política de participación social en la conservación que hasta hoy no se ha legitimado por medio de una ley que proteja los derechos de los habitantes de los Parques, así como la existencia de otros poderes y estructuras en el Estado que contrariaban directamente nuestro quehacer, nos hacía pensar que el cuarto de hora, podía convertirse en 5 minutos y que el cambio del personal en el que los indígenas confiaban, podría debilitar aún más.

Doris Ruales, la coordinadora del Parque Nevado del Huila, trabajó en el municipio de Miranda desde 1997 hasta 2001 y es conocida en el norte del Cauca por su trabajo ambiental y comunitario desde esa época. Doris cree en los procesos que se están desarrollando en el territorio Nasa, pero también busca defender los intereses del Parque en todos sus sectores:

Hemos recorrido todo el Parque y hemos visto la pobreza enorme allí existente; existen zonas muy deprimidas y llenas de problemas organizativos, entre otros; pero Toribío tiene dinero con relación a otras zonas, nosotros los conocemos a ustedes desde hace años y por eso hemos estado apoyando este proceso en el cual creemos.

En cuanto al manejo de la información se debe tener claro qué tipo de información requiere la población según sus necesidades, ya que no se trata de recoger información mediocre sino información que sirva a ustedes mismos. 
También se debe tener en cuenta que si la información es para negociar con los industriales (hace referencia al pago de tasas de agua en la cuenca del río Palo) se debe tener mucha claridad sobre este punto; si fuese así, se deberán medir caudales de agua, hectáreas de páramo quemado, hectáreas de reserva, etc. Se necesitará información precisa y valorada con el fin de negociar y poder lograr reciprocidad.

La propuesta de los empleados del Parque, de trabajar aprovechando el personal sin dejar de reconocer las contradicciones propias del Estado, no fue acogida por los miembros del EEA, por el contrario, durante 2003 se mostraron ambivalentes y poco claros frente a lo que querían, hablaban de "dejar la puerta de su casa entreabierta, sin cerrarla del todo, pero sin abrirla tampoco".

El ambiente se tornaba denso y pesado, gritos, cartas, actas, iban y venían entre Toribío y la sede del Parque en Popayán, sin un mayor avance ni acuerdo, mientras el presupuesto designado para el municipio de Toribío en 2003 permanecía casi intacto por desacuerdos entre las partes.

\section{Doris Ruales:}

A mí me parece que hoy lo que existe es una estrategia de desgaste, y que hoy el hecho de que Nelson Lemus no esté aquí no es una casualidad, porque no ha dejado razón alguna. Propongo que hablemos con los cabildos y veamos si se mantienen o se deshacen las cosas.

Yo quiero saber si no creen en nosotros y si no van a creer; si es así, y todo Toribío lo piensa, pues nos vamos antes de que caiga el ocaso; pero si vamos a trabajar juntos, exigimos que se haga con sinceridad y con un mínimo de confianza, ya que de otra forma no se puede.

Sara Cuéllar, quien fue directora de la UMATA de Toribío durante 7 años, entró a hacer parte del equipo financiado por las Naciones Unidas, tenía amplio conocimiento de la actitud de sus antiguos compañeros de trabajo en los resguardos y dijo en una reunión: "La semilla de la desconfianza que se ha sembrado es muy profunda, y yo veo muy difícil continuar así; si ustedes no creen en Parques, es mejor que nos detengamos y no continuemos más".

Pese a que en muchas ocasiones, los presentes sentimos el desgaste y la incertidumbre o la tristeza porque no era posible avanzar en los acuerdos, los líderes de ambos equipos encontrábamos la forma de superar la crisis, los indígenas eran amables y conciliadores en espacios no institucionales; dejando la puerta entreabierta sin llegar a expresar abiertamente su rechazo al Parque Nevado del Huila. Sin embargo, las actividades política, económica y ambiental se comunican entre sí afectándose mutuamente y la puesta en práctica de los proyectos y convenios se tornaba conflictivo, la resistencia Nasa a las propuestas del Parque se hacia sentir en las preguntas suspicaces del porqué, para qué, y quién es el beneficiado en cada situación.

\section{EL PROYECTO ECOANDINO}

A pesar de que algunos de los miembros del EEA y los servidores del Parque no se encontraban de acuerdo con la implementación del proyecto Ecoandino en Toribío, éste se inició en julio de 2003, quizás porque imperaron los resultados a corto plazo: "las raciones de Ecoandino es apoyo directo y concreto de apoyo a las comunidades". 
La participación de la comunidad Nasa en los talleres de sistemas sostenibles para la conservación fue estimulada por las raciones alimenticias que el proyecto Ecoandino provee a los participantes.

Algunos empleados del Parque justifican la entrega de raciones a campesinos e indígenas porque al entregar los estímulos y al asegurar la comida:

los pobladores tendrán tiempo libre para dedicarlo a sus parcelas con el fin de diversificar los cultivos y sembrar orgánicamente, en vez de tener que jornalear en otra finca, pueden capacitarse y además le ha dado reconocimiento y legitimidad al Parque. También ha permitido poner contrapartidas para la financiación de otros proyectos.

Otros estábamos en desacuerdo con la entrega de raciones porque consideramos que en vez de generar autonomía alimentaría, se creaba dependencia de productos externos. Las raciones del Plan Mundial de Alimentos, fueron creadas para atender a las poblaciones vulnerables que quedan desprotegidas en medio de la guerra de manera temporal, son raciones de guerra; en contraste al requisito de desprotección, una de las exigencias del proyecto Ecoandino es que las capacitaciones y raciones se entreguen a dueños o propietarios de parcelas siempre y cuando asistan a las capacitaciones e implementen la agricultura orgánica. Este mecanismo crea paternalismo por parte del Estado en la población beneficiada, mientras opera de manera excluyente frente a sectores vulnerables de la población como viudas, madres cabeza de familia, ancianos y todos aquellos que no tengan tierra.

Los argumentos de los miembros del Equipo en contra de la implementación del proyecto, se originaban en la dificultad que tendrían para hablar de autonomía alimentaría al entregar tales raciones a las familias, porque ¿cómo podrían hablar de soberanía y seguridad alimentaría con esta metodología?

Según las palabras del Gobernador del Resguardo de Toribío, Heliodoro Yatacue, en la población existía resistencia frente al proyecto; algunas personas se dirigieron a él para preguntarle: "señor Gobernador ¿recibimos las remesas?, si las recibimos ¿qué va a pasar? ¿Será que estamos arrendando la casa?, esta es nuestra casa y si se la quedan, o la vendemos ¿a dónde nos vamos a ir?".

\section{EDUCACIÓN AMBIENTAL}

En el municipio de Toribío el EEA y la UAESPNN desarrollan conjuntamente actividades de capacitación en la escuela ambiental de El Crucero sobre las siguientes temáticas:

1. Pensamiento Nasa y su relación con la naturaleza.

2. Territorio natural: estudia el manejo del tull y los bosques desde lo propio, desde lo externo el manejo de las cuencas hidrográficas.

3. Territorio intervenido: estudia las quemas, las talas, la minería indígena, la cacería y la pesca.

4. Salud y medio ambiente.

5. Reciprocidad ambiental.

6. El Control social, se aprende desde "lo propio" según las regulaciones del the'wala, y desde la jurisdicción especial indígena.

7. Plan de desarrollo, ambiental y de vida. 
Estos siete temas son expuestos por líderes indígenas y por el personal de apoyo de Parques Nacionales, con el fin de tener un enfoque desde lo "propio" y desde lo "externo", y son guiados por los siguientes principios: gestión propia, capacidad administrativa, comercialización a partir de valores propios.

Durante la primera visita que realizó el Equipo de Parques Nacionales a la escuela El Crucero, éste fue presentado como un grupo de personas afines a los procesos comunitarios. El coordinador del Equipo Económico Ambiental explicó a los estudiantes que a pesar de que nosotros pertenecíamos al Estado, éramos contratistas y teníamos cierta libertad de acción y por tal razón no estábamos obligados a cumplir con todas las funciones estatales. Que estábamos allí para apoyar el proceso y proveníamos de procesos comunitarios, por lo cual los estudiantes podrían confiar en el Equipo; eso sí, no olvidando la malicia indígena que siempre había que tener. Finalizó recordando que no debían dar ningún tipo de información a aquellos que venían de afuera, especialmente a los de la CRC, quienes necesitaban información para la cuenca del río Palo.

Esta explicación de nuestras funciones me sorprendió, al saber que para esos jóvenes estudiantes existe una imagen de Estado intruso, masculinizado y dominante, que busca obediencia y sumisión; sumada a la advertencia de que otras autoridades estatales como la CRC pueden hacer preguntas que no deberán obtener ninguna respuesta.

\section{RECUPERACIÓN}

Aunque la apropiación, el control, el manejo, y/o la venta de los "recursos naturales" no es un tema prioritario para los Nasa, los líderes han decidido hacerse cargo de éste porque "entonces nosotros serviremos pa' que nos tomen foto únicamente por que la plata se la llevan ellos".

Hasta el momento, los líderes Nasa han identificado nuevas propuestas económicas y legales que los pueden afectar porque buscan controlar y obtener ganancias en el manejo de la naturaleza. Sin embargo, el estilo occidental del control de los recursos naturales tiene altos costos: identificar cuál es el capacidad de captura de $\mathrm{CO} 2$ a partir de los relictos boscosos, los depósitos de agua subterránea, mercadear productos orgánicos o especiales con sellos de calidad para su exportación, las autorizaciones y licencias estatales para la comercialización de los diferentes productos requieren de métodos, tecnología y capital inexistentes hoy en Toribío.

Pese al esfuerzo Nasa por encerrar ojos de agua o introducirse en el mercado orgánico, aún no se han visto resultados económicos directos y el proceso aún depende en buena parte de la cooperación económica nacional e internacional. El sueño de la autonomía alimentaria, política, territorial, entre otros aspectos, es aún un deber ser, un plan futuro que se desarrolla en el largo plazo y que se ve afectado por acuerdos como el TLC, que coloca a los pequeños productores en una situación de desventaja, frente a los grandes inversionistas.

Una nueva propuesta ha sido presentada por los Nasa para administrar el dinero que se está invirtiendo en su territorio, por parte de Parques. El CRIC ha sustentado ante el PNUD GEF - Biomacizo, el proyecto "Fortalecimiento del ejercicio de la autoridad ambiental propia en territorios indígenas del departamento del Cauca" Popayán, noviembre 4 de 2004, con un presupuesto total de $\$ 1.411 ' 550.000$, sus objetivos son: apoyar a los gobiernos indígenas en el fortalecimiento de su capacidad de administración y gestión ambiental, construir una propuesta metodológica para la ordenación de las áreas de páramo 
en tierras de resguardo, fortalecer la producción sostenible en las zonas indígenas, y poner en marcha un sistema de información ambiental indígena, para el departamento del Cauca.

\section{CONCLUSIONES}

En Colombia se implementa la política de participación social en la conservación, incluyendo nuevos objetivos ambientales y culturales para el manejo de los Parques.

En los Parques traslapados con comunidades indígenas, se han firmado convenios, se han realizado planes conjuntos y se espera llegar a la coordinación entre dos autoridades públicas: las autoridades indígenas y los servidores de las áreas protegidas.

En el caso concreto del Parque Nevado del Huila existe la obligación de preservar los páramos, el agua, las especies de flora y fauna más representativas, y apoyar al pueblo Nasa en la conservación de sus sitios sagrados.

Aunque el Parque cuenta con personal que ha vivido y trabajado en procesos comunitarios de la región antes de ser servidores públicos, quienes quieren apoyar el proceso comunitario trabajando desde lo local por medio de la política de participación social y la firma de convenios entre las partes, la guerra, la realidad social, el proceso de "minimalización estatal" (Sousa \& García, 1999, p. 34) y la "resistencia indígena", lo han convertido en un intermediario entre los intereses locales y los financiadores internacionales (proyecto Biomacizo, Ecoandino), sin lograr concretar beneficios económicos directos por parte del Estado para los pobladores.

En general, el tema medioambiental es un discurso y una preocupación introducida por las autoridades ambientales.

Para mejorar su situación y realizar acciones colectivas, los indígenas se reúnen en asambleas comunitarias, donde debaten el tema económico-ambiental, político, salud, familia, organización y derechos humanos, entre otros. Allí se aportan ideas para construir diagnósticos, planes, proyectos y estrategias para afrontar sus problemas. Generalmente, se analiza teniendo en cuenta el pasado, el presente y el futuro por medio de las preguntas: ¿Cómo era antes?, ¿cómo es ahora? y ¿cuál es el sueño de los Nasa?

En las asambleas y mingas del pensamiento, así como en las reuniones entre líderes y funcionarios, se promueve una estrategia de resistencia frente a los actores y los proyectos foráneos, que puede ser grupal (en marchas, protestas, y eventos), o individual (con el silencio frente a las preguntas de aquellos que no son Nasa para impedir que se fugue la información de los resguardos).

Las estrategias de recuperación y resistencia hacen parte del movimiento indígena Nasa, que ha sido construido por medio del diálogo, las asambleas, la creación de estructuras organizativas, la capacidad de convocatoria de los líderes y la formación de recursos educativos que buscan recuperar la historia y la identidad, dando como resultado una política cultural, que cuestiona a la sociedad mayoritaria en que está inmersa. 
Los líderes indígenas Nasa son los encargados de operativizar esta política cultural. Como autoridades públicas, están encargados de la interacción con los foráneos, conocen las metodologías de planeación y gestión de proyectos, son disciplinados, cumplen horarios y están capacitados para dialogar o enfrentar a otras autoridades que no sean Nasa (al Presidente, la guerrilla, la CRC, los Parques Naturales, etc.) en las discusiones que se relacionan con los resguardos.

También realizan un control sobre la información y las propuestas que entran y salen a su territorio. En la elaboración de sus discursos para la protección de "lo propio", suelen pasar de la argumentación, al grito o del grito al silencio, pero a la hora de ser cuestionados evitan tomar decisiones, transfiriéndolas a la los cabildos y/o a la máxima autoridad, la asamblea comunitaria.

Los líderes han identificado en el tema de la conservación ambiental una oportunidad de financiación y han sabido capitalizar la imagen del indígena conservacionista, el derecho al territorio y la autonomía. Por eso, han creado regulaciones desde el derecho propio o desde la ley de origen buscando un beneficio económico en la conservación de la naturaleza, han hecho proyectos premiados por el Estado y los organismos internacionales, y saben aprovechar cada opción para canalizar recursos destinados a la conservación y a la futura reubicación de los habitantes de los páramos hacia la parte plana.

Los financiadores internacionales apoyan y alientan la defensa del territorio y la autonomía indígena a través de proyectos que subsidian estas iniciativas. Aunque es posible que quieran defender los derechos indígenas, los Nasa desconfían sobre sus intenciones. Piensan que ellos se quieren "quedar con su casa", o que pueden estar abonando el terreno para una negociación futura y directa entre los indígenas y ellos, excluyendo al Estado.

Los líderes Nasa, como principales promotores de los derechos indígenas, han aprendido a utilizar el lenguaje de los financiadores para lograr mayores oportunidades económicas en favor de la población, mediante el empleo de identidades instrumentalizadas que cambian el discurso de acuerdo con el sujeto o el objeto de su solicitud. En el caso particular del Nevado del Huila, la interacción entre los líderes de ambas partes es fuente de ambivalencia y no ha sido posible lograr avances sobre los convenios firmados, en la ejecución de los presupuestos y en el desarrollo de actividades conjuntas, debido a la falta de claridad de los indígenas sobre la conveniencia o no de trabajar con los Parques Naturales.

Dentro de los planes políticos Nasa se encuentra el control territorial, económico y cultural. En materia ambiental, creen que el manejo de los ríos, los páramos, la comercialización de productos orgánicos, las licencias ambientales, etc., son propiedad de los Nasa; pero ven en el Estado y las empresas transnacionales una amenaza constante, con un interés marcado por recursos que ellos consideran suyos, materializado en tratados y leyes que desconocen las regulaciones y acuerdos locales como por ejemplo el ALCA y el TLC, la licitación de los Parques Naturales, las fumigaciones y la guerra. Esta realidad del manejo ambiental ha surgido por presión externa que los ha obligado a responder: "para que otros no se queden con lo de nosotros". La posición indígena expresada en resoluciones, comunicados, protestas, gritos, silencios o marchas busca hacer frente a un "sistema que los está encautivando", pero que también busca el control económico y cultural de los bienes y servicios que se generan en su territorio. 
Cada uno de los actores mencionados considera que tiene la obligación de ejercer acciones sobre la naturaleza y en cuanto sea posible obtener un beneficio de ésta; los intereses internacionales se encuentran representados en la firma de los tratados y la financiación de proyectos, que convierten a la naturaleza en patrimonio común de la humanidad, en un bien colectivo, o en un recurso susceptible de ser valorado económicamente.

Avalados por la asamblea comunitaria, en Toribío, han surgido especialistas indígenas en el tema ambiental, que conocen el lenguaje de las ONG, los fondos de financiación y han obtenido premios y beneficios económicos para su comunidad utilizando la imagen del indígena conservacionista, también "resisten", creando un largo trayecto de permisos y autorizaciones que impiden a los financiadores, las ONG y los Parques obtener la información existente sobre los conocimientos, las plantas, animales y el estado de los páramos de sus resguardos; evitan que salga la información existente en los resguardos, promueven discursos en contra de los beneficios que se generan para las transnacionales, el ALCA y el TLC, las patentes, el ecoturismo en Parques manejado por los empresarios y apoyan la resistencia indígena comunitaria, creando alianzas con los campesinos y negros para protestar frente al sistema que los esta encautivando.

Por medio de la creación de leyes, los Nasa buscan combinar "lo tradicional, lo propio y la ley de origen" con reglamentaciones similares a las de la sociedad mayoritaria para posicionar su propiedad sobre la naturaleza y la autonomía, con el apoyo de todo un pueblo que durante años de diálogo y disertación está convencido de que debe "proteger lo propio" y que los beneficios derivados de la naturaleza en su territorio son de los Nasa y para los Nasa.

\section{BIBLIOGRAFÍA}

- ACIN, CRIC. (2004). Gran minga "marcha" por la justicia, la alegría, la libertad y la autodeterminación de los pueblos. Comunicación electrónica. Consulta realizada el 10 de agosto de 2004.

- ACIN, CRIC, ONIC. (2002). Para continuar con las raíces en la tierra. Conclusiones del Congreso de Jambaló Kiwe we'zenyakj ye'zete uhu'nthaw. Semana del 11 al 16 de noviembre. Popayán: Litografía San José. 69p.

- ALTIERI, Miguel 2003. "Riesgos Ambientales de los Cultivos Transgénicos: una evaluación Agroecológica" En: Ingeniería Genética: Los riesgo. Consulta electrónica realizada en http://www.grn.es/avalls el 21 de agosto.

- Chaves, Margarita. (2001). Discursos de identidad y movimiento indígena en el Putumayo. En Mauricio Archila y Mauricio Pardo (Eds.), Movimientos sociales, Estado y democracia en Colombia (p. 238). CES Unal - ICANH. Bogotá: Talleres Litocamargo.

- Colombia. Asamblea Nacional Constituyente. (1991). Constitución Política de Colombia. Normas Ambientales e Indígenas.

- Correa, Francois. (2000). Política territorial y desarrollo sostenible. En Geografía Humana de Colombia. Tomo VII. Vol. 1, 193-233. Bogotá: Editorial $A B C$ limitada.

- CRIC. (2004, Nov. 4). Fortalecimiento del ejercicio de la autoridad ambiental propia en territorios indígenas del departamento del Cauca. CRIC, ONIC, ACIN, Gobernadores indígenas del Cauca, Alcaldes indígenas del Cauca, Grupo de páramos PROMACIZO. Popayán. 
- CRIC, ONIC, ACIN, Gobernadores indígenas del Cauca, Alcaldes indígenas del Cauca, Grupo de páramos PROMACIZO. (2004). Ponencia del Cauca en la audiencia pública nacional - Senado de la República de Colombia - Proyecto de Ley en Páramos. Bogotá.

- CWK - Cxab Wala Kiwe. (2003a). Resolución No. 00308 - julio, por la cual se reglamenta la participación de las instituciones gubernamentales y no gubernamentales y las organizaciones comunitarias en los convenios y desarrollo de acciones en el territorio de Cxab Wala Kiwe y cabildos indígenas de la zona norte del Cauca.

(2003b). Resolución No. 004 de mayo 31, por medio de la cual se ratifican las autoridades tradicionales que hacen parte de la ACIN como Autoridades Ambientales, en el marco del Derecho Propio y en relación con las leyes Constitucionales.

- El Espectador. (2005). Puja por la privatización. La sangre del Tayrona. Semana del 6 al 12 de febrero, p. 5a. Bogotá.

- El Tiempo. (2004a). El medio ambiente a la deriva. 6 de septiembre, p. 1 y 12. Bogotá.

- (2005). Privados, al Parque. Editorial. Viernes 25 de febrero, p. 1 y 14. Bogotá.

- Escobar, Arturo. (1999). El final del salvaje, naturaleza, cultura y política en la antropología contemporánea. Bogotá: Instituto Colombiano de Antropología ICAN y Centro de Estudios de la realidad Colombiana CEREC. p. 110.

. Antropología y desarrollo. Obtenido el 1 de noviembre de 2004, desde http://www.unesco.org/escobarspa.html

- Escobar Arturo, Álvarez E. Sonia, Dagnino Evel (Eds.). (2001). Política cultural y cultura política. Una nueva mirada sobre los movimientos latinoamericanos. Bogotá: Taurus -ICANH. p. 23 y 30.

- Escobar Arturo y Álvaro Pedroza. (1996). Pacífico: ¿Desarrollo o biodiversidad? Estado, capital, y movimientos sociales en el Pacífico Colombiano. Bogotá: CEREC. p. 15, 34, 110.

- GÓMEZ, Herinaldy. (2000). De la justicia y el poder indígena. Popayán: Editorial de la Universidad del Cauca. p. 34.

- Hardt Michael y Negri Antonio. (2001). Globalization and democracy. Document 11. Vienna. p. 1-12.

- Organización de las Naciones Unidas. (1992). Convenio de diversidad Biológica. Río de Janeiro. p. 1, 2, 8j.

- Organización Internacional del Trabajo. Convenio 169. p. 5, 6, 7.

- Oviedo, Gonzalo. (1999). La perspectiva del WWF sobre la conservación con los pueblos indígenas. Taller sobre experiencias prácticas en gestión de áreas protegidas por los pueblos indígenas en Iberoamérica. UAESPNN, MMA, AECl, Fondo Mundial para la Naturaleza, (WWFADENA), ECODESARROLLO. 29 de noviembre al 5 de diciembre. Cartagena de Indias. p. 1-12.

- Política Nacional de Biodiversidad. Obtenido en agosto de 2003, desde www.humboldt.gov.co

- Pineda, Roberto. (1999). Sembrando la selva. Las raíces culturales de la biodiversidad. Revista Maguare, 14, 264-283. Universidad Nacional, Facultad de Ciencias Humanas. Bogotá: UNIBIBLOS.

- Sousa Santos, Boaventura y García Villegas, Mauricio. (1999). El Caleidoscopio de las justicias en Colombia. Colciencias, ICANH, Universidad de Coimbra - CES, Universidad de los Andes, Universidad Nacional de Colombia. Bogotá: Siglo del Hombre Editores. p. 25-54.

- Ulloa, Astrid. (2001). El nativo ecológico: movimientos indígenas y medio ambiente en Colombia. En Mauricio Archila y Mauricio Pardo (Eds.), 
Movimientos sociales, estado y democracia en Colombia (p. 311). CES Unal - ICANH. Bogotá: Taller Litocamargo.

- Warren Kay B. (2001). Los movimientos indígenas como retos al paradigma del movimiento social unificado en Guatemala. En Política cultural y cultura política. Una nueva mirada sobre los movimientos latinoamericanos (pp. 201-215). Bogotá: Taurus - ICANH.

- Yule, Marcos. (1993). Así cuentan los mayores. Traducción de Oral Nasa. Toribío, Cauca.

\section{GLOSARIO}

Áreas protegidas: el término "área protegida" es entendido como área definida geográficamente que ha sido asignada o regulada y administrada con el fin de alcanzar objetivos específicos de conservación, recuperación, aprovechamiento, entre otros.

Jigra: mochila.

Manejo participativo de áreas protegidas: se refiere a "una alianza establecida de común acuerdo entre los interesados de un territorio o conjunto de recursos amparados bajo el estado de protección para compartir entre ellos las funciones de manejo, derechos y responsabilidades". En el caso de los pueblos indígenas, se trata de arreglos institucionales en donde representantes gubernamentales y/o no-gubernamentales e indígenas entran en un acuerdo formal que específica los derechos, poderes (sobre uso y toma de decisiones), responsabilidades, obligaciones y beneficios de cada una de las partes y sus mecanismos de control, en cuanto al manejo y aprovechamiento de los recursos dentro de un área específica. (Borrini-Feyerabend citado en UAESPNN, 2002).

Minga: "Vamos a explicar para qué es la Minga. Los indígenas nos juntamos dos si se requiere hacer un tull (cultivo tradicional), 10 si vamos a recoger la cosecha, mil si es menester arreglar la carretera, 18 mil si hay que tomar decisiones para el futuro y todos si hay que salir a defender la justicia, la alegría, la libertad y la autonomía" (CRIC et al., 2004).

Nasa tull: huerta Nasa. De acuerdo con Gómez (2000, p. 37), es el espacio de la domesticación de lo humano mediante las normas y su socialización domesticación y de lo natural mediante el cultivo de plantas para su alimentación.

Nasa yuwe: lengua utilizada por los Nasa.

Reciprocidad: valor Nasa. La reciprocidad o el siempre devolver, se encuentra relacionado con la armonía y la solidaridad o siempre ofrecer. "El desequilibrio personal genera transgresión y esta produce desarmonía en el grupo. Por eso es necesario recuperar la armonía social mediante el acto de reciprocidad y cooperación del trabajo y restituir el desequilibrio personal a través de la terapéutica ritual que recompone la armonía de las tay o fuerzas que están presentes y dirigen la vida de todos los seres" (Gómez, 2000, p. 26).

The wala: médico tradicional, en lengua nasa yuwe significa grande o mayor, esta palabra esta escrita según la grafía utilizada en textos publicados por los Nasa del norte del Cauca. 
El the wala es el encargado de autorizar el paso de los comuneros por sitios sagrados (páramos y lagunas), por sus conocimientos en el manejo de las plantas medicinales frías y calientes, además de su comunicación con la naturaleza a través de los sueños, se considera que el the wala es una autoridad importante en la conservación ambiental. También es el encargado de predecir el futuro de la comunidad, vaticinando los desastres naturales o humanos que suceden en el territorio.

Tull: el tull es una huerta diversificada que busca una alimentación balanceada, de buena calidad y libre de químicos, que brinda los alimentos necesarios para la sostenibilidad de una familia con pequeños excedentes para la comercialización.

\section{SIGLAS}

Biomacizo: proyecto financiado por el Global Environment Facility (GEF) del Banco Mundial. La entidad encargada de realizar los desembolsos del proyecto Biomacizo es el PNUD (Programa de las Naciones Unidas para el Desarrollo) y el ejecutor es la Unidad de Parques Nacionales, en convenio con los cabildos indígenas y la alcaldía de Toribío.

CDB: Convenio de Biodiversidad.

CECIDIC: Centro de Educación, Capacitación e Investigación para el Desarrollo Integral de la Comunidad.

CWK: Cxab Wala Kiwe. En lengua Nasa yuwe estas palabras significan "el territorio del gran pueblo". La CWK es una organización indígena que representa a las autoridades indígenas del Norte del Cauca; hasta diciembre de 2002 dicha organización se llamaba Asociación de Cabildos Indígenas del Norte del Cauca $(\mathrm{ACIN})$.

CRC: Corporación Autónoma Regional del Cauca. Autoridad ambiental descentralizada perteneciente al ministerio del Medio Ambiente, Desarrollo Rural y Saneamiento Básico.

CRIC: Consejo Regional Indígena del Cauca. Esta organización representa todas las autoridades indígenas del Cauca.

EEA: Equipo Económico Ambiental del municipio de Toribío. Se encuentra conformado por aproximadamente 48 dinamizadores ambientales. Este grupo es financiado por los cabildos indígenas económico-ambientales de los resguardos de Toribío, San Francisco y Tacueyó, el proyecto Biomacizo - UAESPNN y el proyecto ECOFONDO.

FAA: Fondo para la Acción Ambiental. Su origen es el acuerdo bilateral suscrito entre los gobiernos de Estados Unidos de América y de la República de Colombia, mediante el cual se destinan recursos económicos provenientes de una operación de pago de deuda por naturaleza. Este acuerdo prevé la constitución del Consejo de las Américas, entidad rectora de los recursos del Fondo.

FARC: Fuerzas Armadas Revolucionarias de Colombia. Grupo guerrillero colombiano. 
INCORA: Instituto Colombiano de Reforma Agraria. Actualmente esta institución ha sido sustituida por el INCODER.

PMA: Plan Mundial de Alimentos.

PAI: Plan ambiental indígena.

PNN-NHUILA: Parque Nacional Natural Nevado del Huila.

SSC: Sistemas Sostenibles para la Conservación. Buscan "producir conservando", uno de sus principales componentes es la agricultura orgánica.

UAESPNN: Unidad Administrativa Especial del Sistema de Parques Nacionales Naturales.

UICN: Unión para la Conservación de la Naturaleza.

UNESCO: Organización de las Naciones Unidas para la Educación, la Ciencia y la Cultura.

WWF: World Wild Foundation. Fundación Mundial para la Conservación.

1. Abogada con Magíster en Antropología, docente de teoría del derecho y derecho ambiental de la Universidad de Caldas. Correo electrónico: diana.correa@ucaldas.edu.co

2. Colombia tiene una extensión continental de 114'174.800 hectáreas, que representan aproximadamente $0,7 \%$ de la superficie continental mundial. En esta área se encuentra el $10 \%$ de la biodiversidad mundial, haciendo de Colombia un país "megadiverso" (Política Nacional de Biodiversidad, p. 2).

3. La información se obtuvo en el marco del proyecto PNUD - GEF Biomacizo, para la implementación del convenio firmado por los líderes Nasa y los funcionarios del Nevado del Huila.

4. Sin desconocer su importancia, se encuentran excluidos de este texto la representación que la Unidad Administrativa de Parques Nacionales Naturales hace de los campesinos y las comunidades negras, los cuales tienen un tratamiento legal y político desigual y diferenciado con relación a las comunidades indígenas.

5. De acuerdo con el concepto de gubernamentalidad de Foucault: "Todos los proyectos o prácticas que intentan dirigir a los actores sociales a comportarse de una manera particular y hacia fines específicos, en los que la política gubernamental es sólo uno de los medios de regular o dirigir dichas acciones" (citado en Ulloa, 2001, p. 311).

6. Respecto a las concesiones ecoturísticas: "[...] El primero de estos proyectos es la apertura de las licitaciones, el pasado 3 de febrero, que terminarán con la adjudicación de unas concesiones para manejar el ecoturismo de las ensenadas en Cañaveral y Arrecifes en el Tayrona. "El turismo de hamaca no va a ser de quinta categoría, sino de categoría cien. El mundo va para allá" dijo el presidente 
Álvaro Uribe al anunciar la decisión, concertada con el Gobierno, la Alcaldía de Santa Marta, la Gobernación del Magdalena, la Cámara del Comercio y el sector turístico" (El Espectador, 2005, p. 5a). 